\title{
SELEÇÃO DE FUNGOS FILAMENTOSOS DO BIOMA CAATINGA PARA A PRODUÇÃO DE QUITINASE
}

\author{
J. R. GUIMARÃES ${ }^{1}$, L. S. CORDEIRO ${ }^{1}$, E. C. O. ARAÚJO' ${ }^{1}$, I. R. SILVA ${ }^{1}$, R. J. S. \\ GONÇALVES ${ }^{1}$
${ }^{1}$ Universidade Federal de Campina Grande, Unidade Acadêmica de Engenharia de Bioprocessos e Biotecnologia
E-mail para contato: renatoge74@gmail.com

\begin{abstract}
RESUMO - A Caatinga representa uma crescente potencialidade para o setor da prospecção de microrganismos com características comerciais para produção de metabolitos secundários, dentre os quais se destaca os fungos entomopatogênicos. Nesse contexto, esta pesquisa buscou verificar a existência de variabilidade genética para a produção de quitinase em isolados fúngicos pertencentes à coleção de fungos filamentosos da caatinga. Avaliando o crescimento celular dos genótipos na presença de quitina, bem como quantificando o Índice Enzimático (IE) por meio do Método de Difusão em Gel de Ágar, onde valor superior a dois classificaram os isolados fúngicos como promissores para produção de quitinase. Dentre os 117 isolados fúngicos apenas 45,3\% apresentaram perfil de crescimento. Efeito significativo que mostra a atividade quitinolítica dos isolados fúngicos, indica existência de variabilidade genética e sugere situação favorável para a seleção desses genótipos. Verificou-se, pelo teste de Scott-Knott a 5\% de probabilidade, a formação de três grupos de genótipos com aptidões distintas sendo o CDSA097, CDSA098 e CDSA111 aqueles que apresentaram maior desempenho para variável resposta em estudo.
\end{abstract}

\section{INTRODUÇÃO}

Nas últimas décadas, os fungos vêm se destacando graças a seu enorme potencial em produzir uma infinidade de metabólitos, os quais apresentam diferentes aplicações biotecnológicas como produção de vacinas, enzimas, antibióticos, antifúngicos, anticancerígenos. Alguns podem apresentar maior potencial para a produção de certa enzima. Isso pode ser justificável pela a existência de variabilidade genética neste reino para as diversas características. A maioria dos microrganismos produtores de quitinase são obtidos dos solos, principalmente, ricos em quitina. O principal critério utilizado para selecionar esses microrganismos é avaliar a sua capacidade em utilizar a quitina como única fonte de carbono (AZEVEDO e ARAÚJO, 2006; PAGNONCELLI, 2008; SANTOS, 2008).

As enzimas são proteínas produzidas por todos os organismos vivos. São catalisadores biológicos altamente específicos que aceleram as reações químicas, tais como digestão, respiração, metabolismo e manutenção de tecidos (FOOD INGREDIENTS BRASIL 2011). Atualmente a produção de enzimas movimenta anualmente bilhões de dólares. Segundo Sant'anna Júnior (2001) novas enzimas estão sendo descobertas a partir do trabalho conjunto de equipes de diferentes linhas de pesquisas vinculado às áreas de Microbiologia, Bioquímica, 
Química, Engenharia Bioquímica, entre outras. Parceria que minimiza os custos vinculados à atividade industrial de produção de enzimas.

As enzimas mais utilizadas na indústria são as hidrolases, enzimas que catalisam a quebra de polímeros utilizando a água (THIMOTEO, 2011). Dentre essas enzimas podemos citar: celulase (EC 3.2.1.4); quitinase (EC 3.2.1.14); $\beta$-manosidase (EC 3.2.1.25); glican-1,3$\beta$-glicosidase (EC 3.2.1.75) entre outras.

As quitinases (EC 3.2.1.132) são enzimas glisosilhidrolase que catalisam a reação de hidrólise das ligações glicosídicas $\beta(1 \rightarrow 4)$ presente nos polímeros de $\mathrm{N}$-acetil-glucosamina da estrutura da quitina. Em geral, as enzimas quitinolíticas podem ser classificadas em dois tipos: (i) endoquitinases (EC 3.2.1.14), hidrolisam a quitina de maneira aleatória nas ligações glicosídicas internas, liberando oligossacarídeos de diferentes tamanhos; (ii) exoquitinases, atuam de maneira progressiva pela extremidade redutora da quitina, liberando quitobiose e Nacetilglucosamina (SAITO et al, 1999; RAST et al., 2003; YOUNG et al., 2005; RAMIREZ et al., 2011).

Diante do exposto, nota-se a grande importância de identificar e selecionar isolados fúngicos da Caatinga que apresentem potencial para a produção de quitinase. Avaliando a eficiência do método de seleção empregado, pela estimação dos coeficientes de variação genética, ambiental e da herdabilidade no sentido amplo para a determinação da atividade quitinolítica dos isolados fúngicos.

\section{MATERIAL E MÉTODOS}

O experimento foi desenvolvido no Laboratório de Fitossanidade do Semiárido (LAFISA), da Universidade Federal de Campina Grande (UFCG), Campus Sumé, PB. No presente trabalho foi utilizada a quitina, cedida pelo Laboratório de Avaliação e Desenvolvimento de Biomateriais do Nordeste (CERTBIO). Foi utilizado os 117 isolados fúngicos, pertencentes à Micoteca CDSA do laboratório de Microbiologia da Universidade Federal de Campina Grande.

Para o procedimento de conservação e ativação das células foi utilizado o meio de cultivo sólido básico BDA (20\% de Batata, 1,8\% de Dextrose e 1,5\% de Ágar). A ativação ocorreu em placas de Petri em estufa a $28{ }^{\circ} \mathrm{C}$ durante 7 dias. Posteriormente, para analisar a tolerância (potencial em apresentar perfil de crescimento) e a hidrólise da quitina (parâmetro representado pelo halo de degradação) os isolados fúngicos foram cultivados em placas de Petri contendo meio sintético formulado com a presença de quitina ( $1 \%$ de quitina e $1,5 \%$ de Ágar) e incubados à temperatura de $28^{\circ} \mathrm{C}$ durante 5 dias.

As placas contendo as colônias foram submetidas à coloração específica com solução contendo iodo $\left(3,33\right.$ g.. $\left.\mathrm{L}^{-1}\right)$ e iodeto de potássio $\left(6,67 \mathrm{~g} . \mathrm{L}^{-1}\right)$ por 20 minutos. O halo de degradação representado pelo Índice Enzimático (IE) (Equação 1) foi avaliado como indicativo da capacidade de produção enzimática. Dessa forma, os isolados fúngicos que apresentaram IE superior a dois foram os que possuem melhor potencial para atividade quitinolítica extracelular.

$$
\mathrm{IE}=\frac{\text { diâmetro médio do halo de degradação }}{\text { diâmetro médio de formação de cólonia }}
$$


O delineamento experimental utilizado foi de blocos inteiramente casualizados com três repetições. Cada placa correspondeu a uma repetição. Os tratamentos foram selecionados ao acaso sendo utilizado 30 dos 53 isolados fúngicos que foram capazes de crescer em meio sintético contendo quitina, dentre os 117 presentes na coleção. Os dados referentes ao IE foram submetidos à análise de variância, com os recursos do pacote computacional SAS. As médias dos tratamentos foram comparadas pelo teste de Scott \& Knott. A partir das esperanças dos quadrados médios das análises de variância, foram estimadas a herdabilidade no sentido amplo $\left(\mathrm{h}_{\mathrm{a}}^{2}\right)$, as variâncias genéticas $\left(\sigma_{\mathrm{g}}{ }^{2}\right)$, ambientais $\left(\sigma_{\mathrm{e}}^{2}\right)$ e o índice b, como mostra as Equações 2, 3, 4 e 5, respectivamente.

$$
\begin{gathered}
\mathrm{h}_{\mathrm{a}}^{2}=\frac{\sigma_{\mathrm{g}}^{2}}{\sigma_{\mathrm{g}}^{2}+\sigma_{\mathrm{g}}^{2}} \\
\mathrm{CV}_{\mathrm{g}}(\%)=\left(\frac{\left(\sigma_{\mathrm{g}}^{2}\right)^{0,5}}{\mu}\right) \times 100 \\
\mathrm{CV}_{\mathrm{g}}(\%)=\left(\frac{\left(\sigma_{\mathrm{a}}^{2}\right)^{0,5}}{\mu}\right) \times 100 \\
\mathrm{~b}=\frac{\mathrm{CV}_{\mathrm{g}}}{\mathrm{CV}_{\mathrm{a}}}
\end{gathered}
$$

\section{RESULTADOS E DISCUSSÕES}

Dentre os 117 isolados fúngicos apenas 45,3\% apresentaram perfil de crescimento em meio de cultivo contendo quitina como fonte de carbono e indutora para a produção de quitinase (Tabela 1). Pelo teste do Índice Enzimático (IE), dentre os 10 genótipos selecionados ao acaso, $70 \%$ desses, além de expressarem perfil de crescimento, mostraram capacidade para produção de quitinase.

De acordo com os ensaios, pode-se verificar que houve efeito significativo para a atividade quitinolítica dos isolados fúngicos, indicando, assim, haver variabilidade genética entre eles (Tabela 2). A estimativa do coeficiente de variação ambiental $\left(\mathrm{CV}_{\mathrm{e}}\right)$ foi aproximadamente $545 \%$ inferior ao coeficiente de variação genética $\left(\mathrm{CVe}=15,18 \%\right.$ e $\mathrm{CV}_{\mathrm{g}}=$ $82,79 \%$ ), resultando em valor da razão $\mathrm{b}=\mathrm{CV}_{\mathrm{g}} / \mathrm{CV}_{\mathrm{e}}$, superior a 1,0 . Além disso, a estimativa de herdabilidade no sentido amplo $\left(\mathrm{h}_{\mathrm{a}}{ }^{2}\right)$ foi alta $(98,89 \%)$, o que reforça, mais uma vez, a alta variabilidade genética e também uma situação favorável para a seleção de isolados fúngicos com potencial para produção de quitinase. 
Tabela 1 - Isolados fúngicos pertencente à coleção do Biolab do CDSA/UFCG que apresentaram crescimento em meio contendo quitina como fonte de carbono. UFCG, Sumé, PB, 2015.

\begin{tabular}{llll}
\hline & \multicolumn{2}{c}{ Isolados fúngicos $^{\mathbf{1}}$} & \\
\hline CDSA01 & CDSA35 & CDSA83 & CDSA105 \\
CDSA02 & CDSA49 & CDSA85 & CDSA106 \\
CDSA06 & CDSA50 & CDSA86 & CDSA107 \\
CDSA07 & CDSA54 & CDSA87 & CDSA109 \\
CDSA08 & CDSA56 & CDSA88 & CDSA110 \\
CDSA10 & CDSA61 & CDSA90 & CDSA111 \\
CDSA11 & CDSA62 & CDSA92 & CDSA112 \\
CDSA12 & CDSA68 & CDSA93 & CDSA113 \\
CDSA13 & CDSA70 & CDSA96 & CDSA114 \\
CDSA17 & CDSA73 & CDSA97 & CDSA115 \\
CDSA18 & CDSA74 & CDSA98 & CDSA116 \\
CDSA20 & CDSA78 & CDSA100 & - \\
CDSA22 & CDSA79 & CDSA101 & - \\
CDSA23 & CDSA81 & CDSA103 & - \\
\hline
\end{tabular}

Tabela 2 - Resumo da análise de variância para o índice enzimático de isolados fúngicos.

\begin{tabular}{ccc}
\hline Fontes de variação & GL & Índice Enzimático \\
\hline Blocos & 2 & 0,3293 \\
Genótipos & 9 & $146,8240^{* *}$ \\
Erro & 18 & 1,6274 \\
Média $(\mu)$ & & 8,40 \\
$C V_{\mathrm{e}}(\%)$ & & 15,18 \\
$\mathrm{CV} V_{\mathrm{g}}(\%)$ & & 82,79 \\
$b=\mathrm{CV}_{\mathrm{g}} / \mathrm{CV}$ & 5,45 \\
$\mathrm{~h}_{\mathrm{a}}^{2}(\%)$ & & 98,89 \\
\hline
\end{tabular}

$\mathrm{CV}_{\mathrm{e}}$, coeficiente de variação ambiental; $\mathrm{CV}_{\mathrm{g}}$, coeficiente de variação genético; índice $\mathrm{b}$,

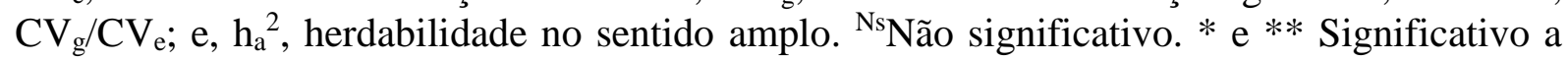
$5 \%$ e $1 \%$ de probabilidade, respectivamente, pelo teste de $\mathrm{F}$.

Por meio das análises do IE pôde-se evidenciar, pelo teste de Scott-Knott a 5\% de probabilidade, a formação de quatro grupos de genótipos com aptidões distintas em sintetizar quitinase (Tabela 3). Dos 10 genótipos testados ao acaso, 70\% apresentam potencial para produção de quitinase, pois suas médias estão acima do ponto de referência (IE $\geq 2,0)$. Os genótipos CDSA097 (IE = 18), CDSA098 (IE = 17,67) e CDSA111 (IE = 14,83) foram aqueles que apresentaram maior desempenho para variável resposta em estudo, sendo enquadrados no primeiro grupo. O segundo grupo (representado pelo genótipo CDSA109, IE = 11,03) apresentou atividade quitinolítica em nível intermediário, enquanto os genótipos CDSA115 (IE = 7,57), CDSA114 (IE = 7,5) e CDSA113 (IE = 7,43) apresentaram resultado inferior aos demais citados acima. No entanto, ainda foi verificado um grupo cujos genótipos 
(CDSA110, CDSA106 e CDSA071) não atenderam os requisitos necessários exigido no presente trabalho.

Tabela 3 - Produção de quitinase por meio de isolados fúngicos pertencente à coleção do Biolab do CDSA/UFCG, avaliados pelo índice enzimático (IE). UFCG, Sumé, PB, 2015.

\begin{tabular}{lc}
\hline Genótipos & IE \\
\hline CDSA097 & $\mathbf{1 8 , 0 0 a} \mathbf{( 1 )}^{(\mathbf{1 0}}$ \\
CDSA098 & $\mathbf{1 7 , 6 7 a}$ \\
CDSA111 & $\mathbf{1 4 , 8 3 a}$ \\
CDSA109 & $\mathbf{1 1 , 0 3 b}$ \\
CDSA115 & $\mathbf{7 , 5 7 c}$ \\
CDSA114 & $\mathbf{7 , 5 0 c}$ \\
CDSA113 & $\mathbf{7 , 4 3 c}$ \\
CDSA110 & $0,00 \mathrm{~d}$ \\
CDSA106 & $0,00 \mathrm{~d}$ \\
CDSA071 & $0,00 \mathrm{~d}$ \\
\hline
\end{tabular}

${ }^{(1)}$ Médias seguidas pela mesma letra pertencem ao mesmo grupo, pelo teste de Scott-Knott, a $5 \%$ de probabilidade de erro.

De maneira geral, quando consideramos todos os 117 isolados fúngicos da coleção, $5,98 \%$ dos genótipos foram selecionados como potenciais produtores da enzima quitinase. É importante evidenciar que nesta coleção os isolados fúngicos não foram identificados segundo a taxonomia e com isso os presentes resultados evidenciados pelo teste de Scott-Knott, a 5\% de probabilidade podem indicar a presença de 4 grupos distintos com genótipos pertencentes ao mesmo gênero e espécie. Isso leva ao questionamento quanto à presença de variabilidade genética na população em estudo, pois os 10 genótipos analisados podem ser reduzido, no mínimo, há apenas 4 classificados fúngicos.

\section{CONCLUSÕES}

- A relação entre a estimativa do coeficiente de variação genética e ambiental e a herdabilidade no sentido amplo foram altas para o índice enzimático, demonstrando a eficiência do método empregado para a seleção de genótipos com maior potencial para produção de quitinase.

- De maneira geral, quando consideramos todos os 117 isolados fúngicos da coleção $5,98 \%$ dos genótipos foram selecionados como potenciais produtores da enzima quitinase.

- Os isolados fúngicos CDSA097, CDSA098 e CDSA111 foram selecionados para estudos que possam promover a otimização do processo de produção da enzima quitinase. 


\section{REFERÊNCIAS}

AZEVEDO, J. L.; ARAÚJO, W. L. Diversidade e aplicações de fungos endofíticos isolados de plantas tropicais. In: GANGULI, B. N.; DESMUCH, S. K. Fungi: Multifacetated Microbes New Dehli: Anamaya Publication, p. 189-207, 2006.

FOOD INGREDIENTS BRASIL. Enzimas: Natureza e Ação nos Alimentos. n. 16, p. 26-37. 2011. Disponível em: <www.revista-fi.com>. Acesso em: 20 fevereiro de 2017.

PAGNONCELLI, M. G. B. Estudo do mecanismo de produção de oligossacarídeos com atividades nutracêuticas a partir da quitosana por hidrólise enzimática com processo fermentativo simultâneo. 2008. 118 p. Tese (Doutorado)- Programa de Pós-Graduação em Engenharia Química, Universidade Federal do Rio Grande do Norte. Natal. 2008.

RAMIREZ, C. C.; SALCIDO, N. M. F. S; CANO, R. D. P.; RODRIGUEZ, T. O.; CORONA, J. E. B. Potencial de los quito-oligosacáridosgenerados de quitina y quitosana. Actauniversiraria. v. 21, p. 14-21, 2011.

RAST, D. M., BAUMGARTNER, D., MAYER, C., HOLlEnSTEIN, G. O. Cell wall associated enzymes in fungi. Phytochem. v. 64: p. 339-366, 2003.

SAITO, J., KITA, A., HIGUCHI, Y., NAGATA, A. Crystal structure of chitosanase from Bacillus circulans MHK1 at $1.6 \AA$ resolution and its substrate recognition mechanism. $J$. Biol. Chem. v. 274, p. 30818-30825, 1999.

SANT'ANNA JUNIOR, G. L. Produção de enzimas microbianas. In: LIMA, U. A.; AQUARONE, E.; BORZANI, W.; SCHMIDELL, W. (Coords.). Biotecnologia industrial - processos fermentativos e enzimáticos. São Paulo: Edgard Blücher Ltda., 2001. p. 351362.

SANTOS, J. B. Melhoramento de plantas visando resistência à doenças. 2008.142 p. Departamento de Biologia, Universidade Federal de Lavras. Lavras. 2008.

THIMOTEO, S. S. Isolamento e Caracterização Molecular de Três Quitinases de uma Biblioteca Metagenômica. 2011. 115p. Dissertação (Mestrado) - Programa de PósGraduação em ciências, Universidade Federal do Paraná. Curitiba. 2011.

YOUNG, V. L., SIMPSON, R. M., WARD, V. K. Characterization of an exochitinase from Epiphyaspostvittananucleopolyhedrovirus (family Baculoviridae). J. Gen Virol. v. 86,p. 3253-3261, 2005. 